\title{
The Relationship between Husbands' Level Of Neuroticism And Wives' Level Of Self-Esteem, Marital Satisfaction And Sexual Desire
}

\author{
Sailee M. Padhye ${ }^{1}$, Jennifer Chandani ${ }^{2}$, Archana Patki ${ }^{3}$ \\ ${ }^{1}$ Post Graduate student, Department of Psychology, Shri. Maniben M.P.Shah Women's College of Arts and \\ Commerce, Mumbai. \\ ${ }^{2}$ Assistant Professor, Department of Psychology, Shri. Maniben M.P.Shah Women's College of Arts and Commerce, \\ Mumbai. \\ ${ }^{3}$ Professor and Head, Department of Psychology, Shri. Maniben M.P.Shah Women's College of Arts and Commerce, \\ Mumbai.
}

E-mail-archanapatki@yahoo.co.in

\begin{abstract}
Introduction: Marriage is the most important event of every individual's life; it not only includes two people but also two different individuals' families as well as their social lives. Many times, their personalities may affect each other's life and physical as well as psychological health. This research focused on, the relationship between husband's level of Neuroticism and wives level of Self Esteem, Sexual Desire and Marital Satisfaction.

Methodology: The research is conducted on Indian copulas with married life of 10 to 20 years. A Purposive Sample is one that is selected based on the knowledge of the population and the purpose of the study. It is where the subjects are selected because of some characteristic which they possess. In this study, the sample selection was done depending upon the level of Neuroticism in husbands. The study is quantitative in nature. Standardized tests are used namely Eysenk's personality questionnaire, The Rosenberg Self Esteem scale which is developed by sociologist Dr. Morris Rosenberg as well as Index of Marital satisfaction was developed by Hudson and The Sexual Desire Inventory-Female (SIDI-F). Results: The research was conducted on 100 married couple with husband's who scored high in Neuroticism. The mean obtained for Neuroticism was 20.34 whereas the mean obtained for self esteem was 18.19. For marital satisfaction the mean score was 68.18 and for sexual desire was 27.06. The standard deviation found to be 1.87 for husbands' level of Neuroticism. The standard deviation found to be 5.56 for wife's Self esteem, the SD of Marital satisfaction was 13.77 and for Sexual desire it was 8.59.

Conclusion: The obtained data shows no significant difference between the husbands' level of Neuroticism and wife's level of Self esteem. There was a positive correlation between the satisfaction. It found that there is low negative correlation between the husband's level of Neuroticism and wife's level of Marital Satisfaction and Sexual Desire. Statistical Analysis revealed that there could be positive or negative correlation between the husbands' level of neuroticism and their wives' Marital Satisfaction and Sexual Desire.
\end{abstract}

Key Words: Husbands, Wives, Neuroticism, Sexual desire, Self esteem, Marital Satisfaction, Relationship.

(Paper received $-11^{\text {th }}$ May 2016, Peer review completed $-5^{\text {th }}$ July 2016, Accepted $-6^{\text {th }}$ August 2016)

\section{INTRODUCTION}

Culture believes that; marriage brings significant stability and substance to human relationships, which is otherwise incomplete. Marriage defined as the state of being united to a person of the opposite sex as 
husband or wife in a consensual and contractual relationship recognized by law [1]. Most of couples decide to marry because they love each other and want to spend the rest of their lives together. In India and many other countries, most marriages are arranged by parents deciding whom their child should marry [2]. The type of marriage plays a very important role in marital life of the couple. A research done in Pakistan stated perceive social support and martial satisfaction would be highly in arranged marriages couples than love marriages couples [3].

Marital satisfaction is a mental state that reflects the perceived benefits and costs of marriage to a particular person. The more costs a marriage partner inflicts on a person, the less satisfied one generally is with the marriage and with the marriage partner [4]. Many times the way the women are treated by her partners affects her wellbeing and happiness. If the wife experience constant pressure, tension and abuse from her partner or family members that could affects her self esteem and confidence, also constant insult or feeling of not being important cause depression and low confidence. Researchers suggested that personality of partner affects the spouse's psychological health and family environment. Personality is a product of the dynamic and unique organization with the individual of psychodynamic structures or systems and their interaction with the environment. Neuroticism is one of the factors that come under personality traits [5].

Neuroticism is a long term tendency to be in a negative emotion state. People with neuroticism tend to have more depressed moods they suffer from feelings of guilt, envy, anger and anxiety more frequently and more deviously than other individuals. The personality trait of neuroticism refers to relatively stable tendencies to respond with negative emotions to threat, frustration, or loss. Individuals in the population vary markedly on this trait, ranging from frequent and intense emotional reactions to minor challenges to little emotional reaction even in the face of significant difficulties. Although not widely appreciated, there is growing evidence that neuroticism is a psychological trait of profound public health significance. Neuroticism is a robust correlate and predictor of many different mental and physical disorders, comorbidity among them, and the frequency of mental and general health service use [6-7].

Various researches concluded that husbands personality affect's, wife's subjective well being. The disturbance in married life could create many other emotional issues and problem in women, such as depression, low self esteem, low confidence and other psychological disorders. Self-esteem is how we value ourselves; it is how we perceive our value to the world and how valuable we think we are to others. Selfesteem affects our trust in others, our relationships, our work and nearly every part of our lives. Positive self-esteem gives us the strength and flexibility to take charge of our lives and grow from our mistakes without the fear of rejection [8-9]. Research has stated that sexual relation or sexual intimacy plays a very important role in marriage but it differs by the gender. Unlike men's main sexual complaint, erectile dysfunction, women's biggest sexual problem is caused by a combination of both mental and physical factors, which aren't likely to be cured by merely popping a pill [10].

Thus the present study aims to examine the following research problem - whether there is a correlation between the level of Neuroticism in husband and wife's' level of Self esteem, whether there is a correlation between the level of neuroticism in husband and wife's level of Marital satisfaction and whether there is a correlation between the level of neuroticism in husband and wife's level of sexual desire.

\section{METHODOLOGY}

The research is conducted on Indian copulas with married life of 10 to 20 years. A Purposive Sample is one that is selected based on the knowledge of the population and the purpose of the study. It is where the subjects are selected because of some characteristic which they possess. The sample obtained was through the -Purposive Sampling Method\| which is a non probability sampling strategy. In this study, the sample selection was done depending upon the level of Neuroticism in husbands.

Scales used in the study -

- Eysenck's Personality Questionnaire (Revised): Eysenk's Personality Questionnaire is a self assessment personality test for administration to normal population. This test assesses the three traits of Extroversion (E), Neuroticism (M), and Psychoticism (P), in addition the test also 
contained a Lie scale (L), designed to assess the degree of socially desirable response. The EPQ-R contains 90 items to measure the three personality dimensions as well as lie scale [11].

- Index of Marital Satisfaction: This test includes 25 items which has to be rated from 1 to 5 raging that is rarely or noneof the time, a little of the time, sometime, a good part of the time and most or all of the time. "Index of Marital Satisfaction" (INS) that were obtained from three separate studies. The scale was found to have a reliability in excess of .90 and it also has excellent discriminate, construct, content, and factorial validity. This test is high in reliability and validity. This test helps the people to understand how happy and satisfied they are from their marriage life [12].

- Rosenberg Self Esteem Scale: It is a widely used measure of self Esteem. The Rosenberg self esteem scale consists of 10 items to be answered on a four point scale ranging from strongly agree to strongly disagree. Five of the items are positively worded while the other five are negatively worded [13].

- Sexual Desire Inventory: The Sexual Desire Inventory-Female (SIDI-F) is a 13-item scale developed as a clinician-administered assessment tool to quantify the severity of symptoms in women diagnosed with hypoactive sexual desire disorder (HSDD). The present investigation assessed the reliability and validity of the SIDI-F as a measure of HSDD severity. Results show that the SIDI-F exhibits excellent internal consistency, with Cronbach's alpha of 0.9 [14].

\section{STATISTICAL ANALYSIS}

Pearson Product moment Correlation was also calculated to investigate the relationship between level of Neuroticism in husbands and wives Self Esteem, Marital Satisfaction and Sexual Desire. Pearson product-moment correlation coefficient is a measure of the linear correlation between two variables $\mathrm{X}$ and $\mathrm{Y}$, giving a value between +1 and -1 inclusive, where 1 is total positive correlation, 0 is no correlation, and -1 is total negative correlation. It is widely used in the sciences as a measure of the degree of linear dependence between two variables.

\section{RESULTS}

The purpose of the above research was to study the relationship between husbands' level of Neuroticism and wives' level of Self Esteem, Marital Satisfaction and Sexual Desire. In the research purpose four tests were used to measure the variables that are level of Neuroticism in husband and Self Esteem, Marital Satisfaction and Sexual Desire in wife. The research was conducted on 100 married couple with husband's who scored high in Neuroticism.

Table number 1 shows the differences in mean scores of Neuroticism, Self esteem, Marital Satisfaction and Sexual desire. The mean obtained for Neuroticism was 20.34 whereas the mean obtained for self esteem was 18.19. For marital satisfaction the mean score was 68.18 and for sexual desire was 27.06. The standard deviation found to be 1.87 for husbands' level of Neuroticism. The standard deviation found to be 5.56 for wife's Self esteem, the SD of Marital satisfaction was 13.77 and for Sexual desire it was 8.59.

Table 1 Mean score of Neuroticism, Self Esteem, Marital Satisfaction and Sexual Desire

\begin{tabular}{|ccc|}
\hline Variable & Mean & Std. Deviation \\
\hline Neuroticism & 20.34 & 1.871 \\
\hline Self Esteem & 18.19 & 5.564 \\
\hline Marital Satisfaction & 68.18 & 13.776 \\
\hline Sexual Desire & 27.06 & 8.592 \\
\hline
\end{tabular}


Table number 2 shows that the Pearson product moment correlation was used to calculate correlation between the husbands' level of Neuroticism and wife's self esteem, marital satisfaction and sexual desire. Table shows that there is a significant correlation between husbands' level of Neuroticism and wife's level of marital satisfaction that is 0.209 at 0.05 level. The table indicates there is low negative correlation between husbands level of Neuroticism and wife's Sexual desire that is -0.226 . The obtained data shows no significant difference between the husbands' level of Neuroticism and wife's level of Self esteem. The table indicates that there is positive correlation between the husbands' level of Neuroticism and wife's marital satisfaction. It found that there is low negative correlation between the husband's level of Neuroticism and wife's level of Marital Satisfaction and Sexual Desire. The table shows the data was significant on a two tailed, that is, there could be positive or negative correlation between the husbands' level of neuroticism and their wives' Marital Satisfaction and Sexual Desire.

Table 2 Correlation between neuroticism and self esteem, marital satisfaction, sexual desire

\begin{tabular}{|lcccc|}
\hline \multirow{2}{*}{ Neuroticism } & $\begin{array}{c}\text { Self } \\
\text { Esteem }\end{array}$ & $\begin{array}{c}\text { Marital } \\
\text { Satisfaction }\end{array}$ & $\begin{array}{c}\text { Sexual } \\
\text { Desire }\end{array}$ \\
& $\begin{array}{c}\text { Pearson } \\
\text { Correlation }\end{array}$ & 0.141 & $0.209^{*}$ & $-0.226^{*}$ \\
\cline { 2 - 5 } & Sig. (2-tailed) & 0.161 & 0.037 & 0.024 \\
\hline * Correlation is significant at the 0.05 level (2-tailed). & & \\
\hline
\end{tabular}

\section{DISCUSSION}

The above research was intended to study the relationship between the husbands'level of Neuroticism and their wives' self esteem marital satisfaction and sexual desire. This study stated that there is correlation between the husband's level of neuroticism and wives self esteem marital satisfaction and sexual desire. According to the result of the correlation table found out no significant difference between the Neuroticism in husbands' and their wives' Self esteem. One of the reason behind the higher level of self esteem were found among wives was their own personality trait and the ability to deal with the situation, in this research the data was collected of both the working and nonworking women, with irrespective of having children or not. The educational background and economics background was not considered.

Indian research has stated that Self-esteem has enormous influence on mental health of women. Selfesteem comprises self-worth and self-image, which affects women's adjustment in various spheres of life. This paper presents relation of age, family income, and family type with self-esteem among women. The study reveals highly significant relation of family type with self-esteem in personal life of women. Significant differences are also found among women in joint, nuclear and extended families, concerning their self-esteem in family relations, career life, and overall self-esteem. Family income has also shown significant association with women's self-esteem in family relations [15].

According to the theory given by Karen Horney on Neuroticism she gave a very different way of viewing Neurosis. Karen stated few needs of Neurotic people and the distorted ways due to which they face difficulties in their lives. Karen said that the Neurotic need for affection and approval, the indiscriminate need to please others and be liked by them. The neurotic need for a partner is for someone who will take over one's life. This includes the idea that love will solve all of one's problems. Again, we all would like a partner to share life with, but the neurotic goes a step or two too far. In such case it can be assumed that people with high neuroticism can be handled by the person who is high in Self Esteem since that person can take a charge of his or her neurotic partner's life and fulfill the partners need [16].

The recommendation can be given by the researchers that is the research could have done on the couple were husbands are low on Neuroticism and can find out their wives self esteem, marital satisfaction and sexual desire, as well as the personality test could have been given to the wives, to see the other 
confounding factors. Also the research can be measure the wife's level of Neuroticism and see the impact on the husband Marital Satisfaction and Self Esteem.

The practical application of this research is, this research can help in find out the various correlations between the conflicts occurs in married couple; also can spread the awareness among people about the importance of having good mental health in partner to have healthy married life. The research can be helpful for the people who are facing difficulties in mate selection for marriage, so that they can take a help of such research which will help them to see the other qualities in the partner.

The researcher assumes that the test giver gave all the honest responses while solving the tests. The test giver was able to read and understand the language of the test, also the participants were enough qualified to give the test.

\section{REFERENCES}

1. Fincham FD, Bradbury TN. The psychology of marriage: Basic issues and applications. Guilford Press; 1990.

2. Desai S, Andrist L. Gender scripts and age at marriage in India. Demography 2010;47(3):667-87.

3. Qadir F, de Silva P, Prince M, Khan M. Marital satisfaction in Pakistan: a pilot investigation. Sexual Relation Ther 2005;20(2):195-209.

4. Gottman JM, Krokoff LJ. Marital interaction and satisfaction: a longitudinal view. J Consult Clin Psychol 1989;57(1):47-60.

5. Bradbury TN, Fincham FD, Beach SR. Research on the nature and determinants of marital satisfaction: A decade in review. J Marriage Fam 2000;62(4):964-80.

6. Costa PT, McCrae RR. Influence of extraversion and neuroticism on subjective well-being: happy and unhappy people. J Personal Soc Psychol 1980;38(4):668-78.

7. Rusting CL, Larsen RJ. Extraversion, neuroticism, and susceptibility to positive and negative affect: A test of two theoretical models. Personal Individ Diff 1997;22(5):607-12.

8. Branden N. The psychology of self-esteem: A new concept of man's psychological nature. Bantam Books; 1971.

9. Campbell RN. The new science: Self esteem psychology. University Press of America; 1984.

10. Berman JR, Goldstein I. Female sexual dysfunction. Urol Clin North Am 2001;28(2):405-16.

11. Eysenck SB, Barrett P, Eysenck HJ. Eysenck personality questionnaire-revised. Pergamon Press; 1984.

12. Cheung PP, Hudson WW. Assessment of marital discord in social work practice: A revalidation of the Index of Marital Satisfaction. J Soc Serv Res 1982;5(1-2):101-18.

13. Robins RW, Hendin HM, Trzesniewski KH. Measuring global self-esteem: Construct validation of a singleitem measure and the Rosenberg Self-Esteem Scale. Personal Soc Psychol Bull 2001;27(2):151-61.

14. LoPiccolo J, Steger JC. The Sexual Interaction Inventory: A new instrument for assessment of sexual dysfunction. Arch Sexual Behav 1974;3(6):585-95.

15. Shukla A, Kapoor M. Sex role identity, marital power, and marital satisfaction among middle-class couples in India. Sex Roles 1990;22(11-12):693-706.

16. Horney K. The neurotic personality of our time. WW Norton \& Company; 1937.

$$
\begin{aligned}
& \text { Acknowledgements - Nil } \\
& \text { Source of Funding - Nil } \\
& \text { Conflict of Interest - Nil }
\end{aligned}
$$

